\title{
A Tour of Luther's Works Un paseo por las obras de Lutero
}

Rafael Lazcano

Universidad Complutense de Madrid rafael.lazcano@gmail.com - https://orcid.org/0000-0002-9483-9944

\section{Fecha recepción 23.01.2018 / Fecha aceptación 11.06.2018}

\section{Resumen}

La obra de Martín Lutero asienta sus raíces en factores culturales, sociales y económicos, madurados en la Alta Edad Media, y que hicieron fecundo el terreno para la proclamación, expansión geográfica y desarrollo doctrinal de la Reforma protestante. Atrapado por la palabra de Dios, el doctor de Wittenberg, un hombre de fe sencilla y sincera, descubre un nuevo modo de relacionarse con Dios por la «sola fe», la «sola gracia», y la «sola Scriptura», de cara a la justificación/salvación del ser humano. Este singular hallazgo desbanca la doctrina de la iglesia católica medieval, el papa y jerarquías eclesiásticas, indulgencias, reliquias y santos, celibato

\begin{abstract}
Martin Luther's work was rooted in cultural, social and economic factors, reached maturity in the High Middle Ages, and provided fertile ground for the proclamation, geographical expansion and doctrinal development of the Protestant Reformation. Trapped by the word of God, Luther, a man of simple and sincere faith, discovered a new way of relating to God by sola fide, sola gratia, and sola Scriptura, faced with the justification/salvation of the human being. This unique discovery defeated the doctrine of the medieval Catholic church, the pope and ecclesiastical hierarchies, indulgences, relics and saints, celibacy and monastic life. Like-
\end{abstract}


y vida monástica. Lutero, asimismo, con la fuerza de su palabra abre un horizonte de libertad sobre la vida humana y la sociedad, un nuevo modo de acceder al mundo y a la sociedad, que orientará la trayectoria de la época moderna y del hombre de nuestros días.

\section{Palabras clave}

Lutero, fe, palabra de Dios, justificación/salvación, Reforma protestante, libertad, mundo moderno wise, Luther through the strength of his word opened up a horizon of freedom for human life and society, a new way of accessing the world and society, which would guide the trajectory taken by humans and modernity to this day.

\section{Keywords}

Luther, faith, the word of God, justification/salvation, Protestant Reformation, freedom, modern world. 


\section{Presentación}

El 31 de octubre de 2017, víspera de Todos los Santos, se cumplieron 500 años (1517-2017) de la difusión de las 95 tesis sobre las indulgencias, escritas de puño y letra por Martín Lutero, fraile agustino, doctor en Artes - Filosofía por la Universidad de Erfurt (1505), doctor en Teología por la Universidad de Wittenberg (1512) y desde el año siguiente catedrático de Sagrada Escritura en la Facultad de Teología de dicha Universidad.

Con el paso del tiempo, el singular acontecimiento de las 95 tesis ha tomado una llamativa notoriedad y singularidad, tanto desde el punto de vista de la historia de la cultura y desarrollo biográfico, teológico e historiográfico, desde donde podamos vislumbrar la originalidad y el profundo alcance de la propuesta lanzada por Lutero al mundo occidental ${ }^{1}$.

1. Cfr. J. H. Claussen, Reformation: die 95 wichtigsten Fragen, München, [2016]; T. Egido, “La recepción de Lutero. Imágen e imágenes”, Anales Valentinos, Nueva Serie, 7, 2017, 7-29; Id., Martín Lutero. Una mirada desde la historia, un paseo por sus escritos, Salamanca, 2017; R. García Villoslada, Martín Lutero, Madrid 1973, 2 vols.; S. H. Hendrix, Martin Luther: visionary reformer, New Haven, 2016; W. Kasper, Martín Lutero: una perspectiva ecuménica, Maliaño (Cantabria), 2016; T. Kaufmann, Martín Lutero. Vida, mundo, palabra, Madrid, 2017; A. Kohnle, A., Martin Luther. Reformator, Ketzer, Ehemann. Leipzig - Holzgerlingen, 2015 ; R. Lazcano, Biografía de Martín Lutero (1483-1546), Guadarrama (Madrid), 2009; Id., Lutero: Una vida delante de Dios, Madrid, 2017; Id., "La figura de Lutero en su contexto histórico", Estudios Eclesiásticos, 93, 2018, 279-333; B. Lohse, Martin Luther. Eine Einführung in sein Leben und Werk, München, 1983, 201-248; V. Leppin, Die fremde Reformation: Luthers mystische Wurzeln, München, [2016]; Lutero y la teología católica. Tender puentes entre formas de pensamiento diferentes, Madrid, 2017 [artículos de H. Blaumeiser, W. Thönissen, T. Dieter y S. Tobler]; Lutero, su obra y su época. F. J. Campos y Fernández de Sevilla, coordinador, [San Lorenzo de El Escorial], 2017; S. Madrigal, "Variaciones históricas en la imagen católica y evangélica de Martín Lutero", Estudios Eclesiásticos, 93, 2018, 335-373; L. Roper, Martin Luther: renegade and prophet, New York, 2016; S. Rostagno, Doctor Martinus. Studi sulla Riforma, Torino, 2015; P. Saavedra, "A Reforma protestante e a modernidade", Grial. Revista Galega de Cultura, 56/218, 2018, 13-29; R. Schwarz, Martin Luther. Lehrer der christlichen Religion, Tübingen, 2015; H. Vall, "Martín Lutero: Sobre la autoridad secular", Pastoral Ecuménica, 34/103, 2017, 15-38. 


\section{La fuerza de la palabra}

Lutero no se formó intelectualmente en la Universidad de París, sino en Sajonia (Alemania), en las universidades de Erfurt y Wittenberg, como acabamos de indicar. En efecto, frente al método escolástico - de silogismos, lenguajes abstractos y repetición de rígidas fórmulas doctrinales -, seguido en la universidad parisina, en las universidades sajonas se postula el retorno a las fuentes del cristianismo, la recuperación de los autores clásicos, griegos y latinos, la lectura, estudio y comprensión de la palabra de Dios y los padres de la Iglesia, con particular acento, respectivamente, en la carta de San Pablo a los Romanos y en las obras del obispo de Hipona, San Agustín.

La nueva doctrina de Lutero brota de la relación directa con la palabra de Dios y el abandono de la escolástica. Dos realidades intelectuales, metodológicas y académicas diferentes, como diverso será el lenguaje y el modo de difundir o propagar las ideas entre las diferentes capas de la sociedad. Tengamos bien presente que Lutero, de pluma ágil, palabra fácil y excepcional ingenio, puso en circulación los eslóganes publicitarios más poderosos de aquella modernidad sacralizada: sola fe, sola gracia, sola Escritura. Además de su fascinante pasión por Dios y por la palabra de Dios nos encontramos con la imprenta de caracteres móviles, invento alemán capaz de multiplicar el número de libros puestos en circulación y garantizar la difusión del pensamiento de Lutero por todo el Sacro Imperio Romano Germánico.

La palabra, oral o escrita, es para Lutero la fuerza que impulsa, renueva y transforma la vida humana, social y religiosa. Su experiencia de Dios, el hallazgo de una nueva doctrina - la justificación-salvación por la sola fe - y la capacidad argumentativa del doctor de Wittenberg muestran, finalmente, que mediante la palabra se constituye nuestro ser como persona y que por medio de ella queda conformada nuestra identidad en sus múltiples facetas. Y, ¿qué decir de la circunstancia orteguiana? De modo breve y simple cabe señalar que la circunstancia no hace por sí misma a la persona, ni a un genio como lo fue Martín Lutero, uno de los más relevantes de Occidente, aunque sí resulta acertado indicar que los factores políticos, sociales y culturales, madurados en la Alta Edad Media, hicieron fecundo el terreno para la proclamación, expansión geográfica y desarrollo doctrinal tanto de la propuesta de Lutero como de la Reforma luterana.

El siglo XV, digámoslo sin ambigüedades, fue una centuria de cambios generales en las artes y en las ciencias naturales y humanas, de decadencia moral y de acelerados experimentos de renovación. No faltó la confusión doctrinal, el uso de lenguajes babélicos en el ámbito filosófico-teológico y en el mundo religioso-espiritual. Todos mientan la palabra «reforma» - príncipes, eclesiásticos, religiosos, teólogos, diplomáticos, humanistas y pensadores -, sin saber bien en qué consistía ni en cómo llevarla a efecto. Unos y otros anhelan verdades creíbles y seguras. En la vida cotidiana afloran los miedos, la conciencia de pecado, la presencia del demonio, la brujería, el sentimiento de piedad y la preocupación por la vida después de la muerte. Los siglos XV y XVI fueron tiempos propicios para el cambio de mentalidad, el asentamiento de la autonomía humana, y el debilitamiento de la Iglesia. Tan solo unos pocos se atrevieron a criticar la autoridad del papa y a cuestionar las enseñanzas teológicas, espirituales y devocionales de la Iglesia medieval. El más osado de todos, Martín Lutero, apoyado en el valor de su palabra y de la palabra de Dios. 


\section{Las indulgencias en 95 tesis}

La carta enviada al arzobispo de Magdeburgo con las 95 tesis sobre las indulgencias está fechada en Wittenberg el 31 de octubre de 1517. El destinatario en vez de responder a Lutero, dio cuenta a Roma del escrito y de las intenciones del insolente monje agustino, que hablaba del santo negocium indulgentiarum, adjuntando a su vez, una denuncia «por herejía», dado que su autor se atrevía a criticar las indulgencias e incluso a cuestionar los intereses económicos del papa.

Después de un mes sin noticias del arzobispo, Lutero confió a sus amigos el contenido de las 95 tesis, a quienes solicitó su parecer. De este modo comenzaron a difundirse privadamente las famosas Tesis, llegando incluso a un público más amplio una vez traducidas del latín al alemán e imprimirse en varios talleres tipográficos, algunos de ellos situados en ciudades bien alejadas de Wittenberg, como Basilea, Leipzig y Nuremberg. Entre diciembre de 1517 y enero de 1518 las Tesis fueron distribuidas por todas las ciudades de Alemania.

El lenguaje empleado en las tesis, además de apodíctico, puntilloso y exigente, ofrece una riqueza de conceptos teológicos nada vulgar, que evidencia el debate académico al que aspiraba mantener Lutero con los más doctos y sobresalientes teólogos. De inmediato las 95 tesis avivaron la animadversión del pueblo alemán contra Roma. Con ellas Lutero puso fuego a la pólvora explosiva preparada durante años en suelo alemán, con el respaldo de príncipes y señores, que conducirá nada más y nada menos que a desafiar el poder del papado, la curia romana y los papistas, entiéndase por ello a obispos, teólogos y profesores universitarios.

Sin embargo, las Tesis en sí mismas, no son ni una rebelión contra Roma, ni la propuesta de una nueva doctrina, sino el parecer de un catedrático de Sagrada Escritura, un hombre medieval, creyente y animado por el espíritu de modernidad, que desea vivir la fe en relación con la Iglesia de modo leal y coherente. La propuesta que aparece en las Tesis no es otra que la renovación de la vida cristiana, doctrina, espiritualidad y devociones de la Iglesia desde la fidelidad a la Palabra de Dios y el anuncio del Evangelio.

La novedad que encontramos detrás de las 95 Tesis hace referencia al paso de la Edad Media a la Edad Moderna. Es decir, la atención puesta en la persona, el despertar de la conciencia - libertad de conciencia - y la importancia del diálogo de la inteligencia para el avance en el conocimiento de la realidad del propio hombre, el mundo y Dios, entendido por Lutero como derecho a exponer las ideas, de ser interrogado y poder defenderse. Una apuesta firme por el diálogo y el entendimiento mediante el debate y la confrontación de ideas, método y desarrollo doctrinal.

\section{Los «libros de reforma»}

Desde la certeza de que la salvación de Dios se hace presente solo por la fe, desplegó Lutero su mayor fuerza creadora, literaria, teológica y espiritual, dando lugar al alumbramiento en 1520 de tres importantes obras, llamadas desde hace un tiempo «libros de reforma», expresión bajo la cual se presenta el proyecto del nuevo cristianismo y su implantación en Alemania. Esta intensa ofensiva de publicaciones lanzada por Lutero no solo marca sus posiciones 
teológicas y consolida el apoyo político de príncipes y señores, sino que establece el modelo evangélico o luterano en sustitución del católico promovido por la Iglesia de Roma.

\subsection{A la nobleza cristiana de la nación alemana²}

Frente a los poderes que dominan el mundo proclama Lutero en esta obra, escrita en agosto de 1520, la reforma del Imperio y de la vida social, bajo la cual subyace la propuesta de una Iglesia germánica en la que los príncipes seculares están llamados a ejercer el poder eclesiástico contra la tiranía de Roma. Este libro, enmarcado en el género de teología política, publicado en alemán, con estilo vigoroso y expresiones populares, entusiasmó a humanistas, nobles y caballeros, religiosos y eclesiásticos resentidos contra Roma, el aristotelismo y la teología escolástica. El éxito editorial no se hizo esperar. Miles de ejemplares fueron puestos a la venta en sucesivas ediciones y reediciones. La confrontación con Roma, ahora convertida en enemiga de los alemanes por los graves abusos de la curia romana, despertaba gran interés en el pueblo alemán. Roma aparece como usurpadora de los derechos de los alemanes y del Sacro Imperio:

Tenemos, escribe Lutero, el nombre del Imperio, pero el papa es el dueño de nuestros bienes... A nosotros, alemanes, se nos ha educado en la llaneza, pero mientras pensamos que somos señores, nos hemos convertido en siervos de los tiranos más astutos; tenemos el nombre, el título y las armas del Imperio, pero sus tesoros, su autoridad, su derecho y libertad están en poder del papa; así el papa devora la carne y nosotros nos encontramos con la cáscara ${ }^{3}$.

El pueblo alemán sentía la necesidad de liberarse del yugo de Roma. El papa era el problema; Lutero la solución. El papado es presentado como la sede del anticristo, y el papa su personificación, por lo que anima al emperador y a los señores, príncipes y nobles cristianos a que recuperen las funciones que les han sido usurpadas por los «romanistas».

Con destreza, sentencia Lutero, levantaron tres murallas para defenderse, sin prestar atención a las reformas que necesitaba la cristiandad, razón por la cual se ha llegado al actual estado de postración. Roma oprime con gestos de servidumbre y desangra a las naciones con numerosos impuestos. Los alemanes están llamados a reaccionar contra el poder de Roma. La primera muralla está asentada, enseña Lutero, en el principio de que el poder eclesiástico se sitúa por encima del poder secular o civil; la segunda muralla se levanta sobre el magisterio supremo del papa y la infalibilidad de la Iglesia; y la tercera muralla está sustentada en la creencia de que nadie más que el papa puede convocar un concilio.

Las murallas romanistas, augura Lutero, caen fácilmente. La primera muralla - el poder eclesiástico situado por encima del secular - se derrumba por el principio del sacerdocio universal y por la igualdad de todos en virtud del mismo bautismo. El clero y el laicado per-

2. Cf. WA 6, 404-469. [Cito las obras de Lutero por la clásica edición Weimarer Ausgabe, WA].

3. Cf. WA 6, 463-464. 
tenecen al mismo estado eclesiástico, siendo la diferencia solamente de oficio o función. La segunda muralla - el magisterio infalible del papa - se desploma más fácilmente todavía, porque «todos somos sacerdotes, y todos tenemos la misma fe, el mismo Evangelio, los mismos

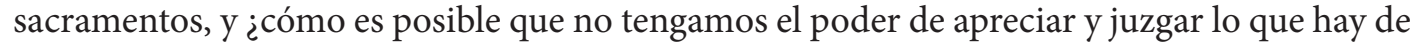
verdadero o falso en el campo de la fe? $»^{4}$. Y la tercera muralla no se sostiene en pie porque no existe argumento alguno que justifique el poder del papa para convocar en exclusiva un concilio, sino que dependiendo de las circunstancias «será preferible que el príncipe convoque un concilio, puesto que él es sacerdote como nosotros, eclesiástico como nosotros, y con potestad como nosotros para todo ${ }^{5}$.

\subsection{La cautividad babilónica de la Iglesia ${ }^{6}$}

El segundo escrito de gran calado doctrinal, más radical y polémico que el anterior, fue redactado por Lutero en dos meses, julio y agosto de 1520. A mediados de la primera semana de octubre veía la luz La cautividad babilónica de la Iglesia romana, obra escrita en latín, puesto que estaba dirigida a los hombres cultos. Cuatro mil ejemplares fueron vendidos en una semana. Lutero había despertado con mucha fuerza el entusiasmo nacionalista en algunos sectores sociales, políticos y religiosos. Aprovecha esta ocasión propicia para defender que la Iglesia se encuentra prisionera del papa, de igual modo que el pueblo de Israel estuvo cautivo en Babilonia, e identifica a Iglesia de Roma con el reino de Babilonia. Ahora se propone derribar el sistema sacramental, santo y seña de la identidad cristiana y vida cotidiana de la Iglesia de Roma. Lutero anima a los alemanes a que se liberen del cautiverio al que Roma ha sometido a los cristianos con la presentación de los sacramentos, convertidos en cadenas y esclavitud que el cristiano arrastra de por vida.

¿De qué cautividades tiene que ser liberada la Iglesia de Cristo? De tres, dice Lutero: a) De la teología de los sacramentos; b) De la doctrina de la transubstanciación eucarística; y c) De la teología del sacrificio de la misa. Veamos las propuestas de Lutero. Los sacramentos instituidos por Cristo no son siete, sino tan solo tres: el bautismo, la penitencia y el pan eucarístico o "sacramento del altar». Tan solo estos aparecen claramente explicitados en la Sagrada Escritura. Los demás signos sacramentales - la confirmación, el matrimonio, el orden sacerdotal (todos sacerdotes), y la unción de los enfermos - no tienen cabida en la propuesta teológica de Lutero. Una vez rota la primera cadena, pasa a la segunda cautividad, afirmando que después de la consagración eucarística el pan sigue siendo pan y el vino también vino, aunque reconozca en ellos por la fe - no por la filosofía escolástica de accidente (transubstanciación) - la verdadera carne y la verdadera sangre de Cristo, en sintonía con la enseñanza del mismo Señor: «este es mi cuerpo; esta es mi sangre» (cf. Mt. 26, 26-28; Mc 14, 22-24; Lc 22,

4. WA 6, 408.

5. WA 6, 413. También recuerda Lutero que el concilio de Nicea (325) no fue convocado por el papa, sino por un laico, el primer emperador cristiano, Constantino i el Grande (272-337).

6. Cf. WA 6, 484-573. 
19-20). Y, finalmente, la tercera cautividad, vinculada al concepto de la misa como sacrificio, cuya explicación ha dado lugar a tantos abusos hasta convertirla en un contrato comercial, se libera porque para «celebrar la misa solamente se requiere la fe, que apoyada fielmente en la promesa, cree que es veraz la Palabra de Dios» ${ }^{7}$.

Un nuevo cristianismo, una nueva Iglesia, a fin de cuenta, promueve Lutero con autoridad doctrinal, unas veces con profundidad teológica, otras con la ingenuidad de un sofista. En todo caso, junto a las quejas y reivindicaciones ofrece nuevas ideas, profundas explicaciones y desarrollos teológicos, sobre todo cuando trata del sacramento del bautismo. Se fija en los sacramentos como expresión de fe y confianza en la gracia. Los postulados principales siguen siendo los mismos: Dios es quien justifica; la justicia de Dios nos salva; el justo vive de la sola fe.

La cautividad babilónica de la Iglesia romana significó una ruptura no solo con la vida cristiana tradicional, sino también con los sentimientos y actitudes derivados de los sacramentos, principalmente en el sacerdocio y la unción a enfermos y moribundos en el trance de la muerte, costumbre tan arraigada en el pueblo cristiano, y particularmente en el suelo alemán.

\subsection{La libertad del cristiano $^{8}$}

En noviembre de 1520, cuando ya había llegado a Wittenberg la bula condenatoria (Exsurge Domine), que requiere la retractación y amenaza con la excomunión, Lutero escribió una obra teológica de gran altura espiritual: La libertad cristiana, ofrecida a modo de «breve suma de la vida cristiana». Sus páginas recogen la doctrina esencial del luteranismo, la justificación por la fe sola, ahora expresada con mayor ponderación, claridad y viveza, sin tonos violentos ni asperezas verbales, puesto que se trata de la liberación interior, espiritual, por la fe.

En efecto, la sola fe hace al hombre libre de toda ley, y quien se dice libre no está sometido a ningún precepto externo. «El hombre cristiano es señor de todas las cosas y a nadie está sometido» ${ }^{9}$. El verdadero cristiano, esto es, el hombre justo, espiritual, interior, no depende de las cosas exteriores, ni de autoridad legislativa y doctrinal que no sea la Sagrada Escritura. Por la fe el hombre es cristianamente libre, y solamente al que cree y confía se le promete la gracia, la justicia, la paz, la libertad de todas las cosas. «De la fe procede la caridad y el gozo en el Señor, y de la caridad, el ánimo libre, gozoso y alegre para servir espontáneamente al prójimo, sin mirar a la gratitud o a la ingratitud, al elogio o al vituperio, al lucro o al daño» ${ }^{10}$.

La libertad cristiana se recibe por la fe a cambio de nada y se transmite en actitud de servicio gratuitamente al prójimo. Esta fe no solo libera, sino que transforma y se apodera del hombre creyente en cuanto ser espiritual, hasta el punto que «el cristiano, sentencia Lutero al final del libro La libertad cristiana, no vive en sí mismo, vive en Cristo y en su prójimo; en Cristo por la fe, y en el prójimo por el amor. Por la fe se eleva sobre sí mismo hacia Dios,

\footnotetext{
7. WA $6,512-513$.

8. WA 7, 20-38 (alemán); 49-73 (latín).

9. WA 7, 21.

10. WA 7, 66 .
} 
por el amor desciende por debajo de él mismo, pero permaneciendo siempre en Dios y en el amor divino, como dice Cristo. Esta es la libertad auténticamente espiritual y cristiana: la que libera al corazón de todos los pecados y preceptos; está por encima de cualquier otra libertad, como lo está el cielo sobre la tierra».

\section{Ruptura con el humanismo de Erasmo: De servo arbitrio ${ }^{11}$ - Sobre el siervo arbitrio o La voluntad determinada}

Cuando un sector del pueblo alemán optó por desvincularse de Roma y la reforma propuesta por Lutero se consideraba una tragedia, se reclamó el parecer del más famoso humanista europeo, Erasmo de Rotterdam. Entre el teólogo bíblico Lutero y el filólogo humanista Erasmo existían profundas diferencias, no solo de talante y formación académica, sino de pensamiento y proyección social. Lutero había sido formado bajo el sistema escolástico; Erasmo en las letras clásicas, la filología y la historia. Ambos estaban enamorados de la Sagrada Escritura, uno como teólogo, exégeta y traductor bíblico; el otro como filólogo, filósofo y pedagogo.

Los rumores de complicidad con Lutero acabaron el día en que Erasmo se propuso combatir la justificación por la fe en su vertiente de la libertad humana, cuestión que aborda en su De libero arbitrio (1524). En la segunda parte de la obra, al final del primer párrafo, expresa que el libre albedrío es «la capacidad de la voluntad humana, gracias a la cual el hombre puede asentir o resistir aquello que conduce a la salvación eterna» ${ }^{12}$. El hombre, según Erasmo, tiene la posibilidad de aceptar o rechazar el camino de la salvación, don gratuito del amor de Dios, en quien depositamos nuestra plena confianza.

La respuesta de Lutero, como no podía ser de otra manera, llegó de inmediato, a finales de 1525 en la obra De servo arbitrio ${ }^{13}$ - Sobre el siervo arbitrio o La voluntad determinada -, obra escrita en latín y traducida en poco tiempo al alemán. La mentalidad de Lutero choca frontalmente contra la de Erasmo, a quien acusa de «impío», «venenoso» e «ignorante» en lo referente a la comprensión de la Sagrada Escritura. «Has de saber, le dice a Erasmo, que éste es el quicio de nuestra disputa...; de esto tratamos, de inquirir qué es lo que puede el libre albedrío, qué es lo que recibe, y cómo se comporta respecto a la gracia de Dios...Todo lo que hacemos, todo cuanto sucede, aunque nos parece mudable y fortuito, de hecho sucede necesaria e inmutablemente...; porque la voluntad de Dios es tan eficaz, que no puede encontrar impedimento siendo la misma potencia natural de Dios, y es tan sabia que no puede engañarse» ${ }^{14}$.

Lutero disiente de la definición de libre albedrío ofrecida por Erasmo. Para el Reformador de Wittenberg compete a Dios solo el libre albedrío. La absoluta soberanía de Dios prevalece

11. WA 18, 600-786.

12. Dice así el texto latino: «Porro liberum arbitrium hoc loco sentimus vim humanae voluntatis, qua se possit homo applicare ad ea, quae perducunt ad aeternam salutem, aut ab iisdem avertere».

13. WA 18, 600-786.

14. WA 18, 615. 
sobre la voluntad humana y su libertad. Así escribe Lutero: «El hombre perdió la libertad, y por fuerza tiene que servir al pecado, y no puede querer nada de bueno». Sí, ciertamente, nuestro obrar nos pertenece, pero es como si fuéramos instrumentos, bien de Dios cuando obramos bien, o bien del pecado cuando obramos mal. Aquí pone Lutero la imagen de la cabalgadura y el jinete que la monta. Dice: «La voluntad humana está puesta en medio, entre Dios y Satán, como un jumento; si la cabalga Dios, la voluntad quiere y va a donde quiere Dios conforme al Salmo 73,22 , «ante ti soy como una bestia, pero siempre estaré contigo». Si la monta Satán, quiere y va a donde quiere Satán; y no está en su arbitrio el dirigirse y buscar a uno u otro jinete, sino que son los jinetes los que luchan por conseguir y poseer el jumento» ${ }^{15}$.

¿Qué nos está diciendo Lutero? Que el hombre no es libre por naturaleza, sino solo como don divino, inseparable de la acción de la gracia recibida por el sacrificio en la cruz de Cristo y manifestada en la fe, que lo libra del pecado, de la ley y de las tradiciones humanas. Lutero parte de una experiencia del pecado y de la justificación por el don gratuito de la sola gracia, y desde ahí adquiere su razón de ser la doctrina del libre albedrío, que no desempeña ningún papel en orden a la salvación. No por méritos humanos el hombre es justificado, sino por la sola gracia de Dios, aunque el hombre siga de continuo atado al pecado. Por una parte, el hombre pecador y la inutilidad salvadora de sus obras; por la otra, la gracia de Dios y la gratuidad de la justificación. La absoluta gratuidad de la gracia conlleva en sí el que el hombre no pueda colaborar con ella. La gracia es eficaz y regenera al hombre y lo justifica aunque el hombre siga siendo lo que era, pecador, puesto que el hombre es, según la clásica expresión de Lutero, «justo y pecador al mismo tiempo» ${ }^{16}$.

\section{La Biblia traducida a lengua vernácula (1534)}

La íntima relación de Lutero con la Sagrada Escritura, el libro de la vida, el libro de libros, el más sabio de todos los que han sido escritos, marcará profundamente la biografía del Reformador alemán. La Sagrada Escritura estará en el centro de las inquietudes de Lutero, una vez que se sintió atrapado por la palabra de $\operatorname{Dios}^{17}$, y en ella encontrará las respuestas a sus angustiosas preguntas y experiencias de salvación ${ }^{18}$. De tal manera llegó a calar en su mente y corazón la palabra de Dios que se convirtió para él en espejo, norma de vida y quehacer teológico, donde Cristo aparece como la piedra angular y eje vertebrador de la vida cristiana.

En la Universidad de Erfurt comenzó la lectura de la Sagrada Escritura. Corría el año 1503. Dos años más tarde recibió de manos del prior del convento agustino de Erfurt un ejemplar de la Biblia, septiembre de 1505, fecha de su ingreso en el noviciado. Desde entonces será un entusiasta e incluso apasionado lector de las Sagradas Escrituras, además de estudioso

15. WA 18, 635.

16. WA 56, 272.

17. WA 7, 838, 4-9; 876, 11 - 877, 6 .

18. Por el contrario el teólogo Melchor Cano, defensor de la fe entendida como asentimiento a las verdades dogmáticas, sostiene que «quien haga teología solo con la fe no cultiva la teología, ni defiende la fe, ni la humanidad»: Melchor Cano, De locis theologicis, libro IX, cap. 4. 
y privilegiado exégeta de sus libros, actividad que llevará a cabo durante 32 años (1513-1545), con ligeras interrupciones, en la cátedra universitaria de la Universidad de Wittenberg.

En atención a los alumnos y pensando en los lectores alemanes de la Sagrada Escritura emprendió Lutero una fecunda actividad intelectual y literaria, como resultó ser la traducción de toda la Biblia al alemán. Aunque existían una veintena de traducciones de la Biblia al alemán, ninguna satisfacía al doctor de Wittenberg porque repetían literalmente la Vulgata latina. Él deseaba una traducción adaptada al pueblo alemán - vocablos, expresiones y refranes populares que usaban niños, mujeres, artesanos y campesinos -, e incluso con añadidos adaptados a la nueva doctrina teológica.

Durante la vida de Lutero aparecieron al menos cuatrocientas treinta - 430 - ediciones de la Biblia o alguna parte de ella. Entre 1534, fecha de la primera edición de la Biblia alemana, y 1584 se calcula la venta de unos cien mil ejemplares ${ }^{19}$. Si el crecimiento de las ciudades y el desarrollo de la burguesía favorecía el fraccionamiento lingüístico, lo que imposibilitaba la creación de una lengua común, Lutero consiguió con la traducción de la Sagrada Escritura la superación de las diferencias dialectales y la creación de un lenguaje común incorporando elementos sintácticos y estilísticos cultos, pero sin perder la vena expresiva popular, puesto que los destinatarios de su obra no eran las personas de la nobleza alemana sino la generalidad del pueblo. Lutero, en efecto, dota y capacita a la lengua alemana, siempre tan sugerente y creativa, como instrumento ancilar para el objetivo religioso. Con la lectura de la Sagrada Escritura en lengua vernácula buscaba la adhesión a la fe en Cristo del hombre común alemán, y el encuentro con Dios, no lejano ni oculto, sino cercano desde la sola fe, misericordioso, generador de confianza y de amor salvífico.

La idea que Lutero ofrece de Dios rompe en mil pedazos el orden tradicional, establecido en cielo, tierra e infierno, cuando afirma:

Dios no es un ser extenso, largo, ancho, gordo, alto, profundo, sino un ser sobrenatural e inescrutable, que a un tiempo está por entero en cada semillita pero también en todas y por encima de todas y fuera de todas las criaturas... Nada hay tan pequeño, que Dios no sea más pequeño; nada tan grande, que Dios no sea más grande; nada tan corto, que Dios no sea más corto; nada tan largo, que Dios no sea más largo, nada tan ancho, que Dios no sea más ancho; nada tan angosto, que Dios no sea más angosto,... Es un ser inexpresable por encima y por fuera de todo lo que cabe nombrar o pensar ${ }^{20}$.

Sirvan estas palabras de colofón, imagen del cosmos abrazado por Dios, Señor del mundo y de la historia que en el Reformado brotaron de la fe, una vez experimentada la gracia de salvación, que arrastra a la búsqueda continua de la verdad sobre Dios, la vida y el mundo desde la inteligencia, la libertad y la autonomía del pensamiento humano.

19. C. Clair, Historia de la Imprenta en Europa, trad. de J. A.Ollero y D. Martín Arguedas, Madrid, 1998, 167 у 175.

20. WA 26, 339-340. 


\section{Conclusiones: Lutero-Reforma-Modernidad}

El aniversario de los 500 años de las Tesis ha puesto de manifiesto, más allás de posibles interpretaciones partidistas de católicos y protestantes, que la Reforma luterana, cuyas raíces se nutren de la teología del medioevo, representa un importante y significativo cambio del orden social, político, económico y religioso.

El catolicismo del siglo XVI había quedado atrapado por una teología y religiosidad medieval, mientras que la propuesta de Lutero, cuyo punto de partida es eminentemente religiosa («sola fe», «sola gratia», «sola Scriptura») y antipapal (crítica acerada del papa, los papistas y la Iglesia de Roma), conducirá tras su condena por la jerarquía eclesiástica a la transformación de la sociedad. La nueva doctrina llevó al fin del universalismo medieval y posibilitó desde el núcleo doctrinal luterano el surgimiento del «hombre moderno», la diferenciación cultural, el pluralismo político y las distintas formas confesionales cristianas.

Las obras literarias de Lutero, arriba presentadas, muestran el itinerario doctrinal y espiritual del Reformador alemán. En ellas descubrimos el legado más decisivo, el meollo doctrinal, el puesto del hombre -justo y pecador al mismo tiempo-, su visión de Dios y de la Iglesia, nuevo Pueblo de Dios. Son estos escritos reformistas los que inauguran, por así decir, la modernidad, o al menos los tiempos pre-modernos, una época nueva, tan compleja como fecunda, que ha contribuido al despliegue de aspectos vitales para comprender la sociedad de nuestros días. 